\title{
AVALIAÇAO DO FILME TRANSPARENTE DE POLIURETANO EM QUEIMADURAS E ÁREAS DOADORAS DE PELE*
}

\author{
Maria Jose da Silva ** \\ Eni-Leci Monteiro de Menezes $* * *$ \\ Yolanda Lopes de Souza *** \\ Nair Colhado Gimenez ***
}

\begin{abstract}
RESUMO - Foram avaliadas pelas autoras a aplicação clínica e técnica de utilização do curativo transparente de poliuretano, num total de cinquenta e cinco pacientes: trinta e três com queimaduras de segundo grau superficiais e vinte e dois submetidos a enxertia de pele. O tempo de permanência dos filmes variou de um a quatorze dias nos dois grupos de pacientes. A utilização do curativo transparente de poliuretano, nestes casos, demonstrou ser uma excelente alternativa, atendendo às necessidades dos pacientes e da equipe médica no que se refere a: ausência de dor, facilidade de aplicação e manuseio, permanência do filme até a completa epitelização dos ferimentos, proteção contra a contaminação, além de proporcionar menor tempo gasto pelo pessoal de enfermagem e redução de custo.
\end{abstract}

\begin{abstract}
The autors have analysed the clinical application and the utilization technique of the transparente polyurethane dressing, used in fifty-five patients; thirty-thee with superficial second degree burns and twenty-two skin graft donor sites. The transparent polyurethane film stayed from one to fourteen days covering the wounds in both groups of patients. The utilization of transparent polyurethane dressing, in these cases, seems to be an excellent alternative to, furfill the patients and staff's needo regarding the following aspects: absence of pain, easy to apply and to handle, permanence of the dressing until the completion of epithelization, protection against contamination, less expense of the staff and low cost.
\end{abstract}

\section{INTRODUÇĀO}

Desde os seus primordios, o homem vem sofrendo agressões que, lesando os seus tocidos, desencadeiam uma sequência biológica natural, no sentido de restaurar a sua integridade.

$O$ processo de cicatrização vem sendo observado e estudado desde o início da história da medicina. Hipocrates dizia: "A cicatrização é uma questão de tempo, mas, às vezes, também de oportunidade". A citação é válida até hoje, relembrando-nos de que é a lesão e não o tratamento, que induz ao fenônemo biol6gico da cicatrização.

Em 1586, Ambroise Paré retoma o princípio da mínima interferência: "A natureza fará a cicatrizaçāo, desde que o mécico não atrapalhe a sua evolução".

Nas altimas décadas, os estudos em biologia molecular trazem à luz a importância daqueles conceitos, enfatizando os cuidados locais, que visam atenuar a destruição tissular e evitar a infecção.

O mecanismo da cicatrização envolve uma sequência de eventos superpostos e interdependentes. Para simplificar, dividiremos o processo em três fases distintas:

1. Inflamatoria: onde ocorre uma migração de leucocitos e eritrocitos para o local da ferida, formando um exsudato e promovendo uma crosta.

2. Fibroplasia: iniciada por volta do $2^{\circ}$ ou $3^{\circ}$ dias após o trauma, onde identifica-se uma população de células (fibroblastos), que apresentam intensa atividade mitótica e de síntese de DNA. Estas células irão formar o tecido de granulação, que possui capacidade contrátil, reduzindo a área cruenta da ferida. Concomitantemente ocorrem a síntese de colágeno e substância fundamental.

3. Maturação: caracterizada pela deposição, agrupamento e remodelação do colágeno, e ainda regressão endotelial, culminando com o reparo da derme e regeneração epidérmica.

Com algumas diferenças na duração e resultados todos os tipos de feridas cicatrizam pelo mesmo processo. Este se inicia no momento exato em que se processa o trauma, mas não atinge a complementação, até que o fator que induzin a lesão tenha sido neutralizado.

A literatura sobre os mais diversos tipos de curativos, que beneficiam a cicatrização, é bastante extensa. Vários materiais, com propriedade químicas e físicas diferentes, têm sido desenvolvidos, com o intuito de atender às necessidades dos diferentes tipos de ferimentos ${ }^{11}$. Esta procura pelo curativo ideal tomou um grande impulso nas últimas duas décadas, com o advento de película transparente de poliuretano, semipermeável e adesiva ${ }^{15,13,1,3,9,6}$. Assim como a pele humana, essa película permite a difusão gasosa e a

* Premio Jaira Cintra Vidal - 2ㅇ lugar - 42을 Congresso Brasileiro de Enfermagem - Natal-RN.

** Enfermeira do Serviço de Controle de Infeç̧ão Hospitalar e ex-enfermeira Supervisora da Clínica de Queimados e Cirurgia Reparadora do Hospital Municipal Dr. Carmino Caricchio.

*** Enfermeiras da Clínica de Queimados e Cirurgia Reparadora do Hospital Municipal Dr. Carmino Caricchio. 
evaporação como a pele humana, essa película permite a difusão gasosa e a evaporação da água do exsudato seroso através dos seus microporos, sendo porém impermeável a fluídos e microorganismos.

Suas principais características são:

- Não aderente às superfí́cies úmidas e aderente às superfícies secas.

- Elasticidade e extensibilidade.

- Estéril e livre de partículas residuais.

- Permeável ao vapor d'água, o que equilibra a hidratação da superfície do ferimento.

- Permite a difusão gasosa de oxigênio e dioxido de carbono, de forma semelhante à pele íntegra.

- Impermeável à água.

- Impede a penetração de bactérias, o que protege o ferimento contra infecções secundárias.

Este estudo teve por finalidade avaliar a aplicação clínica e técnica do curativo transparente do poliuretano, em pacientes vítimas de queimaduras, no que se refere ao atendimento das necessidade dos pacientes e da equipe médica, tais como: diminuição da dor e desconforto, baixo risco de infecção, favorecimento da epitelização, diminuição do tempo gasto na realização e troca dos curativos e redução de custos.

Em nosso meio, é recente a introdução desse esquema de tratamento, sendo este o primeiro estudo com pacientes queimados.

\section{PACIENTES E MÉTODOS}

Foram observados 55 pacientes de ambos os sexos, 33 com queimaduras de $2^{\circ}$ grau superficiais e 22 submetidos a retirada de pele para enxertia.

As idades variaram de 9 meses a 40 anos no grupo de queimados e de 9 anos a 70 anos nos pacientes submetidos a transplante de pele.

Desenvolveu-se um protocolo para o estudo clínico com fichas de acompanhamento individual. Os parâmetros observados foram: tempo de permanência e frequência de troca de filmes, acúmulo de exsudato, fenômenos irrativos da pele adjacente, tempo de epitelização e ocorrência de infecção. Foram analisadas ainda sua praticidade e aplicação.

Somente dois casos de queimaduras foram tratados em regime de internação, devido ao comprometimento de áreas como face e pescoço. O restante dos pacientes foi tratado em ambulatorio. Não foram utilizados agentes tópicos nem sistêmicos neste grupo. A limpeza dos ferimentos foi realizada por debridamento, soro fisiologico e/ou água e sabão neutro. Foram excluídas as queimaduras por agentes químicos e elétricos.

O início do tratamento dos casos variou de 4 horas a 4 dias apos o acidente sendo que, 25 pacientes foram atendidos com menos de 24 horas. Dos casos restantes, 7 estiveram entre 24 e 72 horas e 1 único paciente foi atendido no $4^{\circ}$ dia após a queimaduras.

Todos os casos de áreas doadoras de pele foram auto-enxertos, retirados de coxa e tratados em regime de internação. Utilizaram-se a faca de Blair e o dermátomo de Padget, para a retirada da pele, sendo que a espessura do enxerto ficou na faixa intermediária, variando de paciente para paciente. Para ajudar na hemostasia foram colocadas compressas de soro fisiol6gico gelado, logo apos o procedimento, por um pedíodo de 30 a 45 minutos. Em 7 (30\%) dos pacientes, foi utilizada solução de adrenalina 1:1000, em soro fisiologico a $0,9 \%$, na concentração de 1:120.000, por 5 minutos.

Outra alternativa para alcançar a hemostasia foi o enfaixamento, com atadura de crepe, durante 24 horas, lembrando-se que, nos casos onde a adrenalina é utilizada, pode ocorrer sangramento tardio após o ef eito rebote da mesma ou por elevação da pressão arterial.

Em todos os casos o desengorduramento da pele adjacente foi realizado com benzina ou similar.

Nos casos onde houve excesso de exsudato procedeu-se a sua aspiração por punção com agulha hipodérnica estéril, colocando-se um remédio de um novo filme, no orifício da punção.

O controle bacteriológico foi feito através da colheita de material dos ferimentos, com cotonetes, imediatamente antes da colocação do filme, no primeiro dia de tratamento.

\section{RESULTADOS}

No grupo de pacientes com queimaduras do 2 grau superficiais, de um total de 33 pacientes, 22 $(66,7 \%)$ foram acompanhadas até a completa epitelização dos ferimentos.

Dos $11(33,3 \%)$ pacientes restantes, 5 abandonaram o tratamento e 3 apresentaram epidermite. Em 1 dos pacientes veriricou-se, apos a colocação do filme, que a queimadura era de $3^{\circ}$ grau, inviabilizando a continuidade do uso. $\mathrm{O}$ tratamento com o filme transparente de poliuretano foi interrompido em 2 pacientes, por descohecimento de um dos membros da equipe. No que se refere ao grupo de áreas doadoras de pele, os 22 pacientes estiveram sob o regime de internação, sendo acompanhados até a completa epitelização dos ferimentos (tabela 1).

O escaldo foi o agente mais comum no grupo dos pacientes queimados (tabela 2).

O tempo de permanência dos filmes variou de 1 a 14 dias nos dois grupos de pacientes. Vale a pena ressaltar que a pouca prática da equipe, no início do estudo, em manusear e avaliar os filmes antecipou as trocas em muitos casos, diminuindo o tempo de permanência. Isto deveu-se principalmente a não observância da área de fixação na pele íntegra, que deve ser no mínimo de $3 \mathrm{~cm}$ ao redor do ferimento, e a um desengorduramento ineficiente anterior à colocação, que podem provocar $\mathbf{o}$. deslocamento dos filmes (tabela 3 ).

De cada grupo avaliado, $10(45,5 \%)$ pacientes não tiveram os seus curativos trocados até a completa epitelização dos ferimentos. No restante dos pacientes foram promovidas até 2 trocas de curativos durante todo o tratamento pelos motivos expostos acima (tabela 4).

O tempo médio para a epitelização dos ferimentos variou, no grupo dos pacientes queimados, entre 5 a 9 dias em $17(77,3 \%)$ pacientes. Os $5(22,7 \%)$ pacientes restantes tiveram os seus ferimentos epitelizados no intervalo de 10 a 14 dias. Enquanto que, nos pacientes com áreas doadoras de pele, $13(59,1 \%)$ estiveram na faixa de 5 a 9 dias e $9(40,9 \%)$ entre 10 e 14 dias (tabela 5). 
A relação entre o acúmulo de exsudato e o tempo de absorção pelo organismo, sem necessidade de trocas dos filmes, foi um dos parâmetros analisados, verificando-se que $10(45,5 \%)$ pacientes em cada um dos grupos apresentaram o fenômeno. Destes, $6(60 \%)$ pacientes portadores de queimaduras tiveram o exsudato absorvido no período de 24 a 48 horas enquanto que no mesmo número de pacientes, do grupo de áreas doadoras de pele, foi observada a absorção entre 3 e 5 dias (tabela 6).

É importante a cautela na observação deste exsudato, porque o seu aspecto não é agradável e a quantidade pode impressionar, levando a equipe a trocas e manuseios desnecessários, uma vez que o exsudato pode ser aspirado e o organismo se encarrega de reabsorvê-lo quando não há infecção.

Não houve evidência clínica de infecção em nenhum dos casos tratados, ressaltando-se que dos pa-; cientes de áreas doadoras de pele, $17(77,3 \%)$ estavam em uso de antimicrobianos por ocasião da enxertia. Não foi necessário portanto, o acompanhamento bacteriológico em nenhum dos pacientes avaliados.

O tempo gasto pelo pessoal de enfermagem na colocação, observação e troca dos curativos foi reduzido em pelo menos $60 \%$, comparando-se com o tempo dispendido anteriormente com os curativos tradicionais.

Realizando-se um estudo de custo comparativo, verificou-se que o curativo com filme transparente de poliuretano fica em média $60 \%$ mais barato que o curativo tradicional nos dois procedimentos estudados (tabelas 7 e 8 ).

\section{DISCUSSÃo}

Até bem pouco tempo atrás, o curativo tradicional utilizado no esquema de tratamento de queimaduras de $2^{\circ}$ grau superficiais e áreas doadoras de pele, implica na utilização de apositos de rayon, gazes de rolo, algodão hidrofilo e faixa crepe. Este curativo era trocado de acordo com as necessidades até a epitelização dos ferimentos, o que correspondia, aproximadamente, em uma troca a cada 48 horas, durante 2 semanas em média. Além disso, este tipo de curativo provocava grande desconforto ao paciente, maior risco de infecção, custo elevado e maior tempo dispendido pela enfermagem.

Em um estudo comparativo em pacientes queimados, verificou-se que a dor experimentada com o curativo transparente é bem menos intensa do que com o curativo convencional ${ }^{12}$.

Avaliando a experiência com o curativo transparente de poliuretano no tratamento de queimaduras,
CONKLE ${ }^{7}$ se refere ao ceticismo de parte do staff quando da introdução desta nova alternativa. Após algum tempo, o curativo já era utilizado em cerca de $90 \%$ das queimaduras tratadas. A autora cita ainda a ausência de crosta e uma cicatrização mais rápida e mais eficiente. Além disso, o tempo dispendido pela enfermagem nos cuidados com os curativos caiu pela metade.

Vários estudos clínicos referentes a avaliação do currativo transparente em área doadoras de pele se referem às vantagens da sua utilização, tais como: a redução considerável de dor, índices muito baixo de infecção, auxílio na cicatrização e custo reduzido ${ }^{4} 214$ 85 .

Este estudo veio corroborar os resultados obtidos com o filme transparente de poliuretano como curativo em queimaduras de $2^{\circ}$ grau superficiais e áreas doadoras de pele.

As vantagens verificadas pela sua utilização foram:

1. Ausência da dor, pela cobertura total das terminações nervosas, diminuindo consideravelmente o desconforto.

2. Facilidade de aplicação e manuseio.

3. Redução em pelo menos $60 \%$ do tempo gasto pela equipe com a realização, troca e observação dos curativos.

4. Permanência dos filmes atê a completa epitelização, quando não há complicações e se a equipe estiver familiarizada com o procedimento.

5. proteção da ferida contra a contaminação.

6. Liberdade total de movimentação do paciente.

7. Possibilita a completa higienização do paciente, sem haver necessidade de troca do curativo.

8. Permite o acompanhamento da evolução do ferimento através da sua visualização, evitando assim a instalação de infecção.

9. Proporciona excelente cicatrização, por manter a umidade na superfície da ferida, evitando a formação de crostas, o que resulta em uma cicatrização uniforme, de qualidade estética superior.

10. Custo total reduzido em média $60 \%$.

\section{CONCLUSÃo}

Avaliando-se as vantagens acima mencionadas, concluiu-se que o filme transparente de poliuretano, pode ser recomendado como excelente alternativa, nos casos de queimaduras de $2^{\circ}$ grau superficiais e áreas doadoras de pele, por atender a maior parte dos requisitos de um curativo ideal, principalmente no que se refere a dor e ao conforto dos pacientes, prevenção de infecção, tempo gasto pela equipe, qualidade estética da cicatrização epitelial e custo reduzido. 
TABELA 1

Casos estudados

\begin{tabular}{l|cc}
\hline $\begin{array}{l}\text { Motivo do término } \\
\text { do tratamento }\end{array}$ & Queimaduras & No de pacientes \\
\cline { 2 - 3 } & & $\begin{array}{c}\text { Areas doadoras } \\
\text { pele }\end{array}$ \\
\hline Cura & 22 & 22 \\
Abandono & $(66,7 \%)$ & $(100 \%)$ \\
Outros & 5 & 0 \\
\hline Total de pacientes & $(15,1 \%)$ & 0 \\
\hline
\end{tabular}

TABELA 2

Agentes causadores das queimaduras de 20 grau superficiais

\begin{tabular}{lc}
\hline Agente & No de pacientes \\
\hline Escaldo & 20 \\
Fogo & $(60,6 \%)$ \\
Vapor & 4 \\
& $(12,1 \%)$ \\
Contato & 6 \\
& $(18,2 \%)$ \\
\hline Total de pacientes & $3 \%$ \\
\hline
\end{tabular}

* Dos 33 pacientes, apenas 22 foram acompanhados até o final do tratamento.

Dos demais, 5 abandonaram e em 6 ocorreram intercorrências relacionadas ao manuseio inadequado dos curativos.

TABELA 3

Tempo de permanência dos filmes

\begin{tabular}{l|cc}
\hline \multirow{2}{*}{$\begin{array}{l}\text { Intervalo } \\
\text { (dias) }\end{array}$} & \multicolumn{2}{|c}{ o de pacientes } \\
\cline { 2 - 3 } & Queimaduras & Areas doadoras \\
\hline $1-4$ & 8 & 6 \\
$5-9$ & $(36,4 \%)$ & $(27,3 \%)$ \\
& 11 & 14 \\
$10-14$ & $(50 \%)$ & $(63,6 \%)$ \\
& 3 & 2 \\
\hline Total de pacientes & $(13,6 \%)$ & $(9,1 \%)$ \\
\hline
\end{tabular}

TABELA 4

Frequêencia de trocas dos filmes

\begin{tabular}{c|c|c}
\hline \multirow{2}{*}{ No de trocas } & \multicolumn{2}{|c}{ № de pacientes } \\
\cline { 2 - 3 } & Queimaduras & Areas doadoras \\
\hline Nenhuma & 10 & 10 \\
& $(45,5 \%)$ & $(45,5 \%)$ \\
1 & 9 & 7 \\
2 & $(40,9 \%)$ & $(31,8 \%)$ \\
& 3 & 5 \\
Total de pacientes & $(13,6 \%)$ & $(22,7 \%)$ \\
\hline
\end{tabular}

TABELA 5

Tempo médio de epitelização

\begin{tabular}{l|c|c}
\hline \multirow{2}{*}{$\begin{array}{l}\text { Intervalo } \\
\text { (dias) }\end{array}$} & \multicolumn{2}{|c}{ NNo de pacientes } \\
\cline { 2 - 3 } & Queimaduras & Areas doadoras \\
\hline $5-9$ & 17 & 13 \\
$10-14$ & $(77,3 \%)$ & $(59,1 \%)$ \\
& 5 & 9 \\
\hline Total de pacientes & $(22,7 \%)$ & $(40,9 \%)$ \\
\hline
\end{tabular}


TABELA 6

Acúmulo de exsudato e tempo de absorção pelo organismo sem haver necessidade de troca dos filmes *

\begin{tabular}{l|c|c}
\hline \multirow{2}{*}{ Tempo } & \multicolumn{2}{|c}{ No de pacientes } \\
\cline { 2 - 3 } & Queimaduras & Areas doadoras \\
\hline $24-48$ horas & 6 & 4 \\
3 - 5 dias & 3 & 6 \\
6 - 10 dias & 1 & 0 \\
\hline Total & 10 & 10 \\
\hline
\end{tabular}

* Em um total de 22 pacientes de cada grupo, 12 (54,5\%) não apresentaram acúmulo de exsudato.

TABELA 7

Material, tempo e número de trocas necessárias à realização dos curativos, quando não há intercorrências.

\begin{tabular}{|c|c|c|c|}
\hline Grupo & Material para 1 curativo & Trocas & $\begin{array}{c}\text { Tempo Gasto } \\
\text { (minutos) }\end{array}$ \\
\hline $\begin{array}{l}\text { Queimaduras } \\
\text { de } 2^{\circ} \text { grau } \\
\text { superficiais }\end{array}$ & $\begin{array}{l}\text { Curativo Tradicional } \\
\text { - Ataduras (crepe, algodão, ortopédico, gaze e rayon) } \\
\text { - Soro fisiologico } \\
\text { - Luvas de procedimento } \\
\text { Curativo Transparente } \\
\text { - Soro fisiologico } \\
\text { - Luvas de procedimento } \\
\text { Compressas de gaze } \\
\text { C Eter ou benzina } \\
\text { 2 filmes BioclusiveR } \\
10,2 \text { cm x } 12,7 \mathrm{~cm} \\
\text { Seringas } 5 \mathrm{ml} \\
\text { - Agulha descartável }\end{array}$ & $\begin{array}{l}\text { 1\% atendimento } \\
+2 \text { trocas } \\
\text { Não há trocas. } \\
\text { (Somente no } \\
\text { primeiro aten- } \\
\text { dimento) }\end{array}$ & 60 minutos \\
\hline $\begin{array}{l}\text { Areas doado- } \\
\text { ras de pele }\end{array}$ & $\begin{array}{l}\text { Curativo Tradicional } \\
\text { - Ataduras (crepe, algodão ortopédico, gaze e rayon) } \\
\text { - Vaselina } \\
\text { Curativo Transparente } \\
\text { - } 2 \text { filmes BioclusiveR } \\
10,2 \mathrm{~cm} \text { x } 25,4 \mathrm{~cm} \\
\text { - Eter ou benzina } \\
\text { - Atadura de crepe } \\
\text { - Seringa } 5 \mathrm{ml} \\
\text { - Agulha descartável }\end{array}$ & $\begin{array}{l}1^{\circ} \text { antendimen- } \\
\text { to }+4 \text { trocas } \\
\text { Não há trocas }\end{array}$ & $\begin{array}{l}1 \text { hora } \mathrm{e} \\
15 \text { minutos } \\
20 \text { minutos }\end{array}$ \\
\hline
\end{tabular}

* - Não foi levado em conta o tempo gasto na cirurgia.

TABELA 8

Custo individual dos curativos nos casos sem intercorrências

(Base: majo/90)

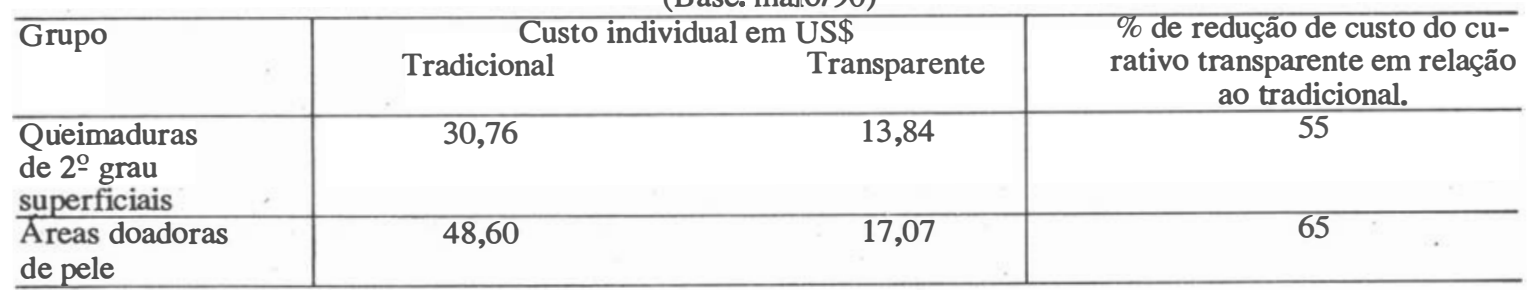

\section{REFERÊNCIAS BIBLIOGRÁFICAS}

1 AHMED, MC. Op-site for decubitus care. Am J Nurs 82: 61-64, 1982.

2 ALLING, P.NORTH A. F. Polyurethane film for coverage of skin graft donor sites. $J$ Oral Surg, 39: 970-971, 1981.

3 ALPER, J. C., WELCH,E. A., GINSBERG, M. Moist wound healing under a vapor permeable membrane. J Am Acad Dermatol, 8: 347-353, 1983.
4 BERGMAN, R.B.TOLHURST, D. E. A comparative trial of skin donor site dressings. Chir plast (Berl). 4: 137-142, 1978.

5 BERGMAN, R.B. A new treatment of split-skin graft donor sites, Arch Chir Neerl 29: 69-71, 1977.

6 CALDWELL, F.T. BOWSER, B.H. CRABTREE, J.H. The effect of occlusive dressings on the energy metabolism of severely-burned children. Ann Surg, 193 (5): 579-591, 1981. 
7 CONKLE, W. Op-Site dressing: New approach to burn care. J Emerg Nurs, 7: 148-152, 1981.

8 DINNER, M.I. PETER, C.R. SHERER, J. Use of a semipermeable polyurethane membrane as a dressing for split skin graft donor sites. Plast Reconst Surg 64 (1): 112-114, 1979.

9 EAGLSTEIN, W.H. Experiences with biosynthic dressings. J Am Acad Dermatol, 12 (2): 434-440, 1985.

10 ELY, J.F. Cinírgia Plástica. Rio de Janeiro: Guanabara Koogan, 1980, 685 p.

11. HIEN N T, PRAWER S E, KATS H I: Facilitated wound healing using transparent film dressing following mohs micrograpfhic surgery. Arch Dermatol 124: 903-906, 1988.
12. NEAL D E, WHALLEY P C, FLERVERS M W: The effect of an adherent polyurethane film and conventional absorbent dressing in patients with small partial thickness burns. Br J Clin Pract 35: 254-257, 1981.

13 SEBERN, M.D. Pressure ulcer management in home health care: efficacy and cost effectiveness of moisture vapor permeable dressing. Arch Phys Med Rehabil, 67 (10): 726-729, 1986.

14 SMITH, D. Treatment of skin graft donor sites with a semipermeable polyurethane dressing. $J$ Oral Maxil Surg, 41: 61-65, 1983.

15 TINCKLER, L. Surgical wound management with adhesive polyurethane membrane: A preferred method for routine usage. Ann R Coll Surg Engl,65: 257-259, 1983. 